\title{
Coaxial Conjugated Polymer/Quantum Rod Assembly into Hybrid Nanowires with Preferred Quantum Rod Orientation
}

\author{
Jun Ho Hwang, ${ }^{+, \S}$ Seon-Mi Jin, ${ }^{+, \$}$ Jinwoo Nam, ${ }^{\ddagger}$ and Eunji Lee ${ }^{*,+}$ \\ Correspondence to: Eunji Lee (eunjilee@gist.ac.kr)
}

\begin{abstract}
${ }^{\dagger}$ School of Materials Science and Engineering, Gwangju Institute of Science and Technology (GIST), Gwangju 61005, Republic of Korea

* Graduate School of Analytical Science and Technology, Chungnam National University, Daejeon 34134, Republic of Korea
\end{abstract}

\section{Solution-Biphase Method vs. One-Pot Addition Method}

(a)

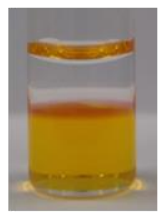

(b)

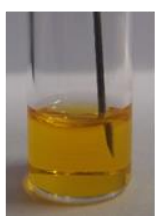

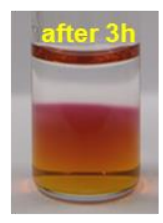

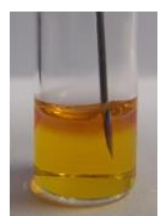

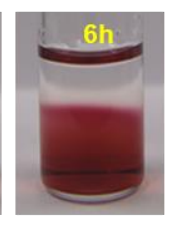

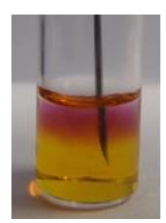

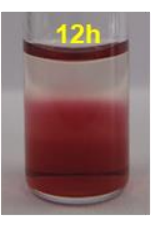

Solution-biphase method Interfacial crystallization-driven assembly

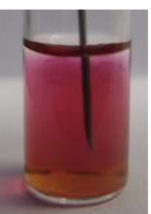

One-pot addition method

Figure S1. A series of optical photographs representing (a) solution-biphase (top) and (b) one-pot addition methods (bottom) to induce the crystallization-driven assembly of poly(3-hexyl thiophene)- $b$-poly(2vinylpyridine) (P3HT-b-P2VP)/QDs. In the micrographs of (a), the upper layer in the vial is acetonitrile, and bottom layer is P3HT- $b$-P2VP dissolved in chloroform $(1 \mathrm{mg} / \mathrm{mL}$ of P3HT- $b$-P2VP/QDs, 2:1 (v/v) ratio of chloroform/acetonitrile). 


\section{SUPPORTING INFORMATION}

\section{Synthesis}

Synthesis of P3HT- $\boldsymbol{b}$-P2VP. P3HT- $b$-P2VP was synthesized according to the procedures as reported previously. ${ }^{\mathrm{S} 1}$ Briefly, as a first block, P3HT-based macro chain transfer agent (P3HT macro-CTA) was successfully prepared using a two-step approach involving Suzuki-Miyaura and subsequent DCC coupling reactions. First, P3HT-Br polymer $\left(M_{\mathrm{n}}=5.8 \mathrm{~kg} / \mathrm{mol}\right.$, PDI $\left.=1.18, \mathrm{DP}_{\mathrm{n}}=35\right)$ with $92 \%$ regioregularity was produced by varying the ratio of 5-bromo-3,3'-dihexyl-2,2'-bithiopheneto 2-bromo-3-hexylthiophene in polymerization. Then, the palladium-catalyzed Suzuki-Miyaura coupling of P3HT-Br with the tetrahydropyranyl (THP) ether-protected boronic acid ( $p$-THPOC ${ }_{6} \mathrm{H}_{4} \mathrm{~B}(\mathrm{OH})_{2}$ ), followed by aqueous $\mathrm{HCl}$ deprotection, provided the desired phenolic P3HT. Subsequently, P3HT macro-CTA was produced via the esterification of the terminal hydroxyl group of P3HT with the carboxyl group of the trithiocarbonate agent in the presence of $N, N^{\prime}$ dicyclohexyl carbodiimide (DCC) and 4-(dimethylamino)pyridine (DMAP). Finally, P3HT- $b$-P2VP was obtained via reversible addition-fragmentation chain transfer (RAFT) polymerization by using P3HT macro-CTA. The resulting products were purified by sequential Soxhlet extractions using methanol, hexane, and chloroform, respectively.

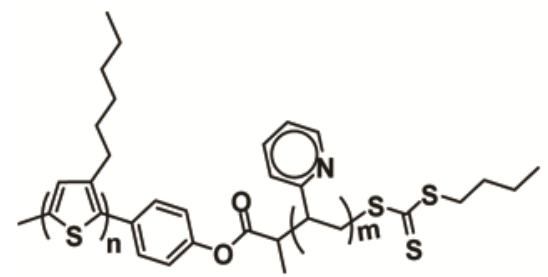

Scheme S1. Chemical structure of P3HT- $b$-P2VP.

(a)

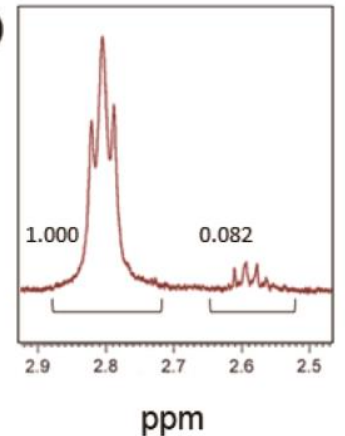

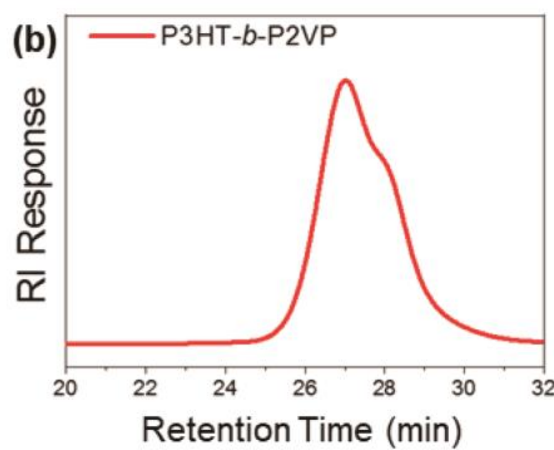

Figure S2. (a) Expanded region from ${ }^{1} \mathrm{H}$ NMR of P3HT block showing the $92 \%$ regioregularity. (b) GPC trace of P3HT- $b$-P2VP with THF as eluent. 


\section{SUPPORTING INFORMATION}

Table S1. Characteristics of synthesized P3HT- $b$-P2VP used in the study

\begin{tabular}{|c|c|c|c|c|c|c|c|c|}
\hline \multirow[b]{2}{*}{ Polymer } & \multicolumn{2}{|c|}{ P3HT } & \multicolumn{2}{|c|}{ P3HT- $b$-P2VP } & \multirow{2}{*}{$\begin{array}{c}M_{\mathrm{n}, \mathrm{P} 2 \mathrm{VP}} \\
\left(\mathrm{g} \cdot \mathrm{mol}^{-1}\right)^{b}\end{array}$} & \multirow{2}{*}{$\begin{array}{c}\text { Repeating } \\
\text { units } \\
\text { P3HT/P2VP }\end{array}$} & \multirow{2}{*}{$\begin{array}{l}\text { wt } \% \\
\text { of } \\
\mathrm{P} 2 \mathrm{VP}^{b}\end{array}$} & \multirow{2}{*}{$\begin{array}{c}\text { Regioregularity }^{b} \\
(\%)\end{array}$} \\
\hline & $\begin{array}{c}M_{\mathrm{n}} \\
\left(\mathrm{g} \cdot \mathrm{mol}^{-1}\right)^{a}\end{array}$ & $\mathrm{PDI}^{a}$ & $\begin{array}{c}M_{\mathrm{n}} \\
\left(\mathrm{g} \cdot \mathrm{mol}^{-1}\right)^{a}\end{array}$ & $\mathrm{PDI}^{a}$ & & & & \\
\hline P3HT- $b-\mathrm{P} 2 \mathrm{VP}$ & 5,800 & 1.18 & 10,500 & 1.57 & 4,600 & $35 / 44$ & 45 & 92 \\
\hline
\end{tabular}

${ }^{a}$ Determined from GPC in THF calibrated by polystyrene standards. ${ }^{b}$ Determined from ${ }^{1} \mathrm{H}$ NMR.

Synthesis of TOPO-Capped CdSe QRs. ${ }^{\text {S2 }}$ The CdSe QRs were prepared in "air-free" conditions under argon gas. The cadmium precursor is prepared by a mixture of $25 \mathrm{mg}$ of Cadmium oxide (CdO), $2.0 \mathrm{~g}$ of tri- $n$ octylphosphine oxide (TOPO) and $150 \mathrm{mg}$ of $n$-tetradecylphosphonic acid (TDPA) at $80{ }^{\circ} \mathrm{C}$ for $2 \mathrm{~h}$. It was done to ensure dissolved oxygen was significant enough to oxidize TOPO in an observable amount. At temperatures above $320{ }^{\circ} \mathrm{C}$, the color of the solution gradually changes from a dark red to a clear colorless, indicating the formation of the Cd precursor. The selenium precursor prepared by dissolving $0.16 \mathrm{M}$ of Se powders in $4 \mathrm{~mL}$ of tri- $n$-octylphosphine (TOP) and heating to $60^{\circ} \mathrm{C}$. The Se:TOP solution was optically clear, colorless, and had no visible Se powders. At the $270{ }^{\circ} \mathrm{C}$ the $0.16 \mathrm{M}$ Se:TOP was swiftly injected, in the CdO/TOPO/TDPA solution and the solution temperature dropped down to $230{ }^{\circ} \mathrm{C}$. Growth of the $\mathrm{CdSe} \mathrm{QRs}$ was performed at $260{ }^{\circ} \mathrm{C}$. Growth was allowed to continue for $5 \mathrm{~min}$, then allowed to cool to $50{ }^{\circ} \mathrm{C} .5 \mathrm{~mL}$ of toluene was injected and the QRs were then precipitated with $10 \mathrm{~mL}$ of methanol. Three precipitation and decantation cycles were repeated by dispersing the QRs to toluene and precipitating with methanol. After purification, the CdSe QRs dissolved in chloroform.

\section{Synthesis of TOPO-Capped CdSe/CdS Quantum Tetrapods (QTs). ${ }^{\mathrm{S} 34}$ 1) Synthesis of Zinc Blende (ZB)-}

CdSe Seeds. In methanol, $\mathrm{Cd}$ nitrate and $\mathrm{Na}$ myristate were combined to provide $\mathrm{Cd}$ myristate. $0.17 \mathrm{~g}$ of $\mathrm{Cd}$ myristate was dissolved in $37 \mathrm{~mL} 1$-octadecene and degassed at $90{ }^{\circ} \mathrm{C}$ for $1 \mathrm{~h}$ in a $50 \mathrm{~mL}$ three-neck flask. 0.024 $\mathrm{g}$ of Se powder was added to the mixture after cooling to room temperature. The reaction mixture was degassed at $50{ }^{\circ} \mathrm{C}$ for $15 \mathrm{~min}$ under vacuum and heated to $240{ }^{\circ} \mathrm{C}$ under $\mathrm{N}_{2}$. When the reaction mixture reached $240{ }^{\circ} \mathrm{C}, 1$ $\mathrm{mL}$ of oleic acid and $1 \mathrm{~mL}$ of oleylamine in $4 \mathrm{~mL}$ of 1-octadecene were added. The growth of CdSe can be controlled by measuring the UV-Vis and PL spectra of aliquots taken at various time intervals. Typically, it takes about $\sim 30 \mathrm{~min}$ for $\sim 3 \mathrm{~nm} \mathrm{ZB}-\mathrm{CdSe}$ seeds to grow. The reaction mixture was allowed to cool to ambient temperature before being transferred to a $\mathrm{N}_{2}$-filled glovebox to isolate the seeds. By adding ethanol to the crude solution, ZB-CdSe seeds were precipitated, centrifuged, and redispersed in anhydrous toluene. The precipitation/redispersion treatment was conducted several times. 2) Synthesis of TOPO-Capped CdSe/CdS QTs: CdSe/CdS tetrapods were generated by growing CdS arms on ZB-CdSe seeds. $0.207 \mathrm{~g}$ of CdO, $1.08 \mathrm{~g}$ of $n$ octadecylphosphonic acid (ODPA), $0.05 \mathrm{~g}$ of $n$-propylphosphonic acid (PPA), and $3.35 \mathrm{~g}$ of TOPO were degassed in a $25 \mathrm{ml}$ three-neck flask at $120{ }^{\circ} \mathrm{C}$ for $1 \mathrm{~h}$. The mixture turned into a clear solution when it was heated to $280{ }^{\circ} \mathrm{C}$ under $\mathrm{N}_{2}$, after which the solution was cooled to $120^{\circ} \mathrm{C}$ and degassed for $2 \mathrm{~h}$. To synthesize the tetrapod, the reaction mixture was then heated to $300{ }^{\circ} \mathrm{C}$. When temperature reached $300{ }^{\circ} \mathrm{C}, 1.5 \mathrm{~g}$ of TOP was 


\section{SUPPORTING INFORMATION}

injected into the solution. Then $0.65 \mathrm{~g}$ of trioctylphosphine sulfide (TOPS) was injected into the solution, followed after $40 \mathrm{~s}$ by the injection of seeds ( $2 \mathrm{mg} \mathrm{ZB-CdSe}$ seeds) in $0.5 \mathrm{~g}$ of TOP. The reaction temperature was gradually increased to $315^{\circ} \mathrm{C}\left(\sim 1{ }^{\circ} \mathrm{C} / \mathrm{min}\right)$ and maintained at that temperature for $20 \mathrm{~min}$ before cooling to room temperature. The yield of tetrapods was controlled using different amounts of PPA. The synthesized QTs were shown in Figure S13.

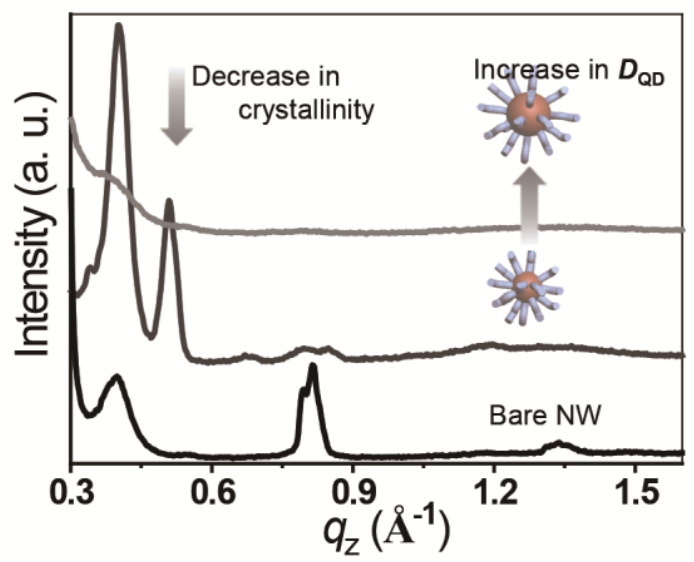

Figure S3. Out-of-plane line cut $\left(q_{\mathrm{z}}\right)$ profiles from GI-WAXS patterns as-cast thin film of P3HT- $b-\mathrm{P} 2 \mathrm{VP} / \mathrm{QD}$ solutions containing hybrid NWs as a function of QD size: (bottom) bare NWs, and after addition of (middle) 4 $\mathrm{nm}$ QDs and (top) $\sim 7 \mathrm{~nm}$ QDs, respectively. $D_{\mathrm{QD}}$ indicates a diameter of QD.
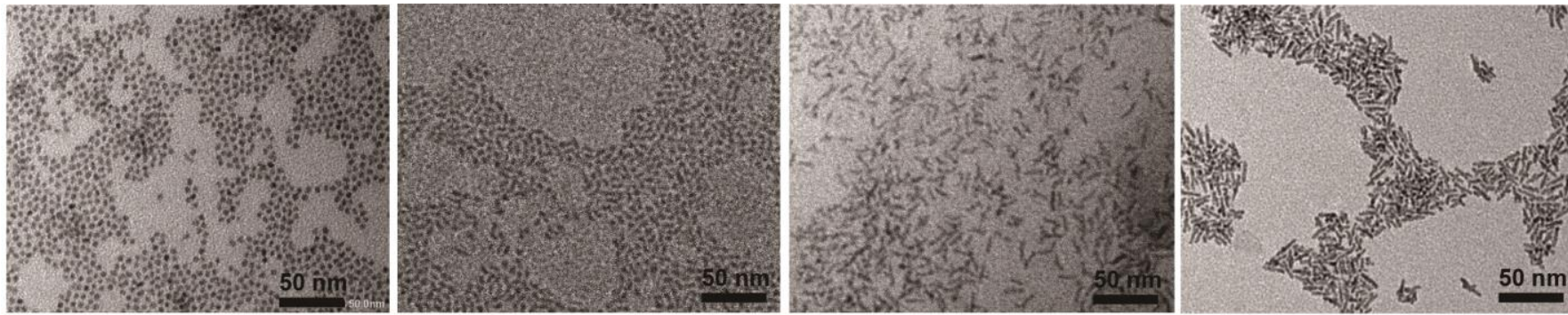

High aspect ratio of diameter to length

Figure S4. Synthesis of TOPO-capped CdSe QR with different aspect ratios of diameter to length. The seed diameter is $\sim 4 \mathrm{~nm}$. 


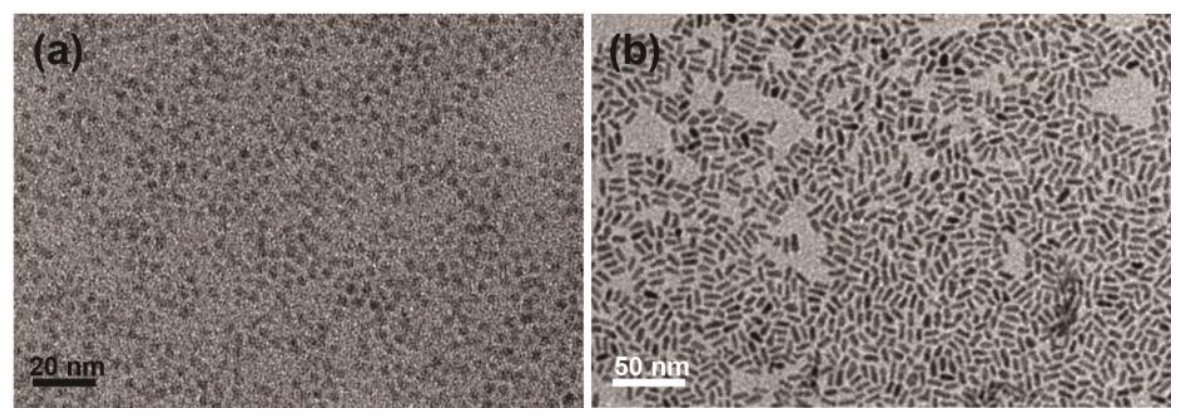

Figure S5. TEM images of TOPO-capped (a) CdSe QDs and (b) QRs used in this study.

(a)

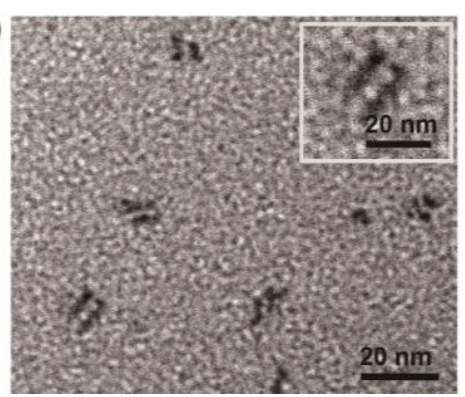

(b)

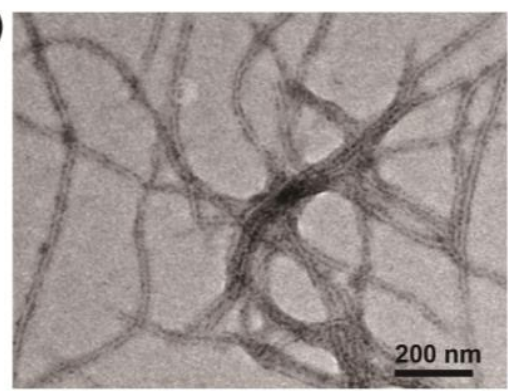

(c)

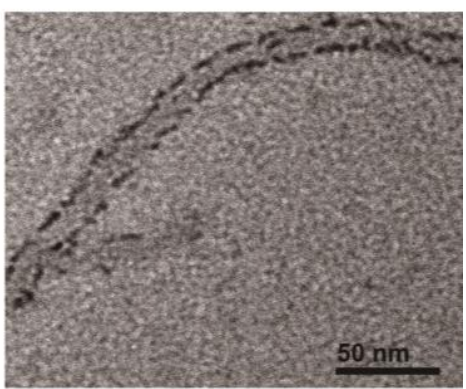

Figure S6. TEM images showing the structural evolution of P3HT- $b-\mathrm{P} 2 \mathrm{VP} / \mathrm{QRs}$ hybrid NWs formed by solution-biphase method: (a) dimeric crystal seeds (with a interparticle distance of $\sim 9 \mathrm{~nm}$ ) and (b) micrometerlong hybrid NWs. (c) Enlarged image of (b) representing the end-to-end QR array confined in a NW. 


\section{SUPPORTING INFORMATION}

(a) Solution-biphase method

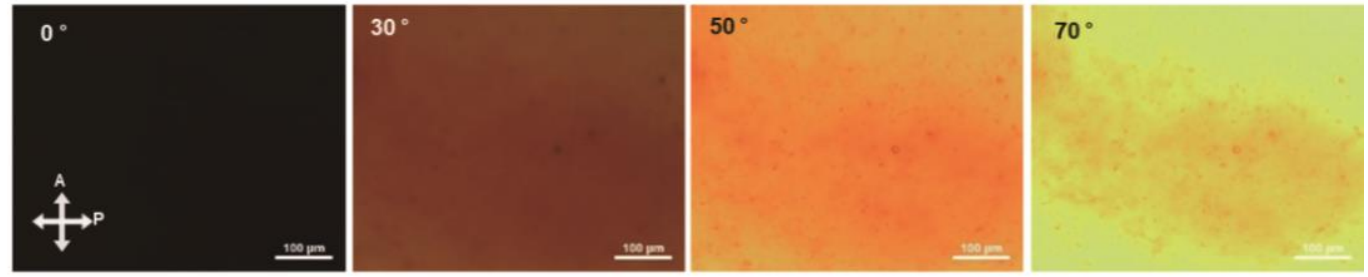

(b) One-pot addition method

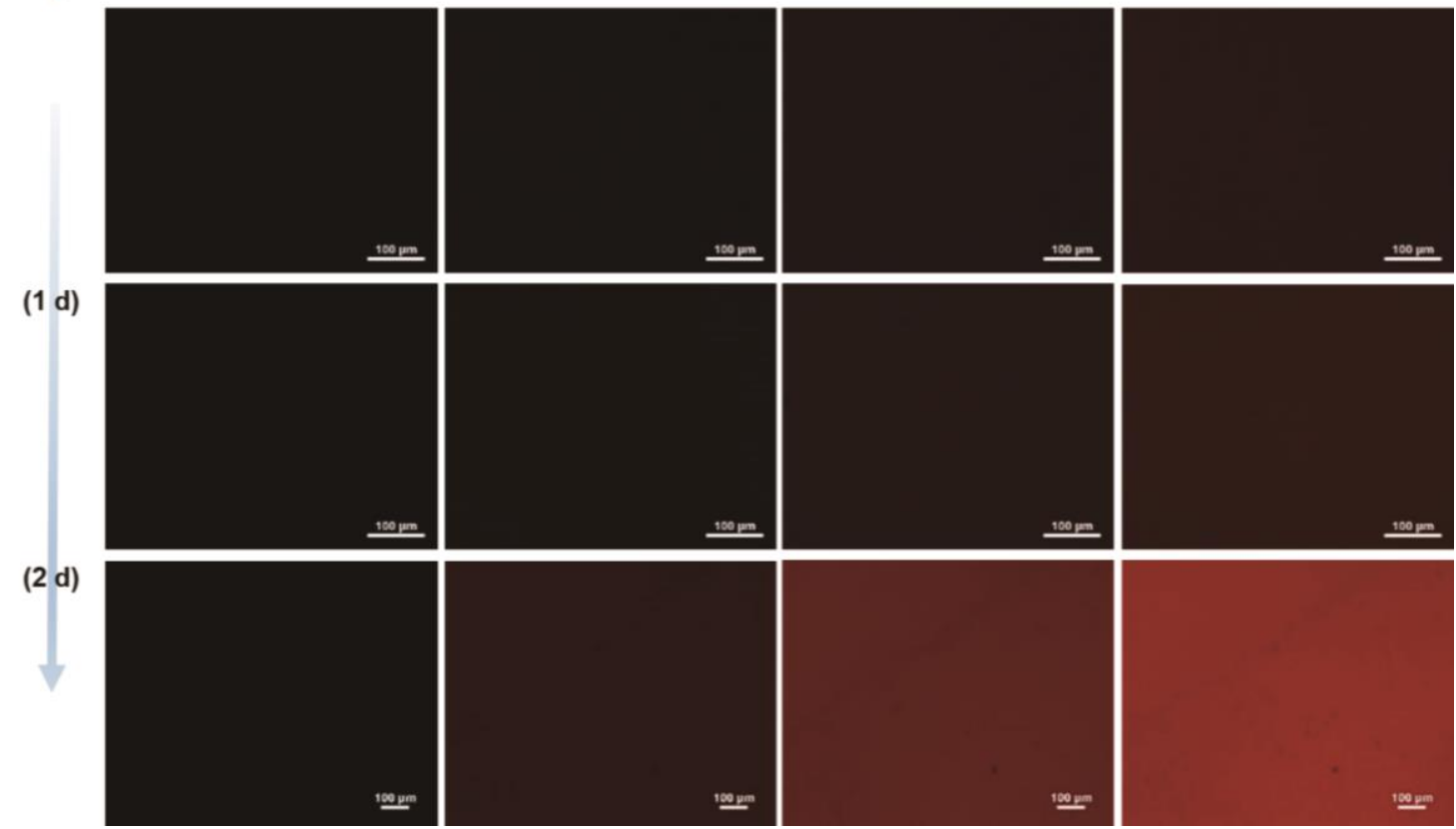

Figure S7. Polarized optical micrographs of P3HT- $b-\mathrm{P} 2 \mathrm{VP} / \mathrm{QRs}$ hybrid NW solutions prepared by (a) solutionbiphase and (b) one-pot addition methods. The degree of rotation between crossed polarizer is labeled. 

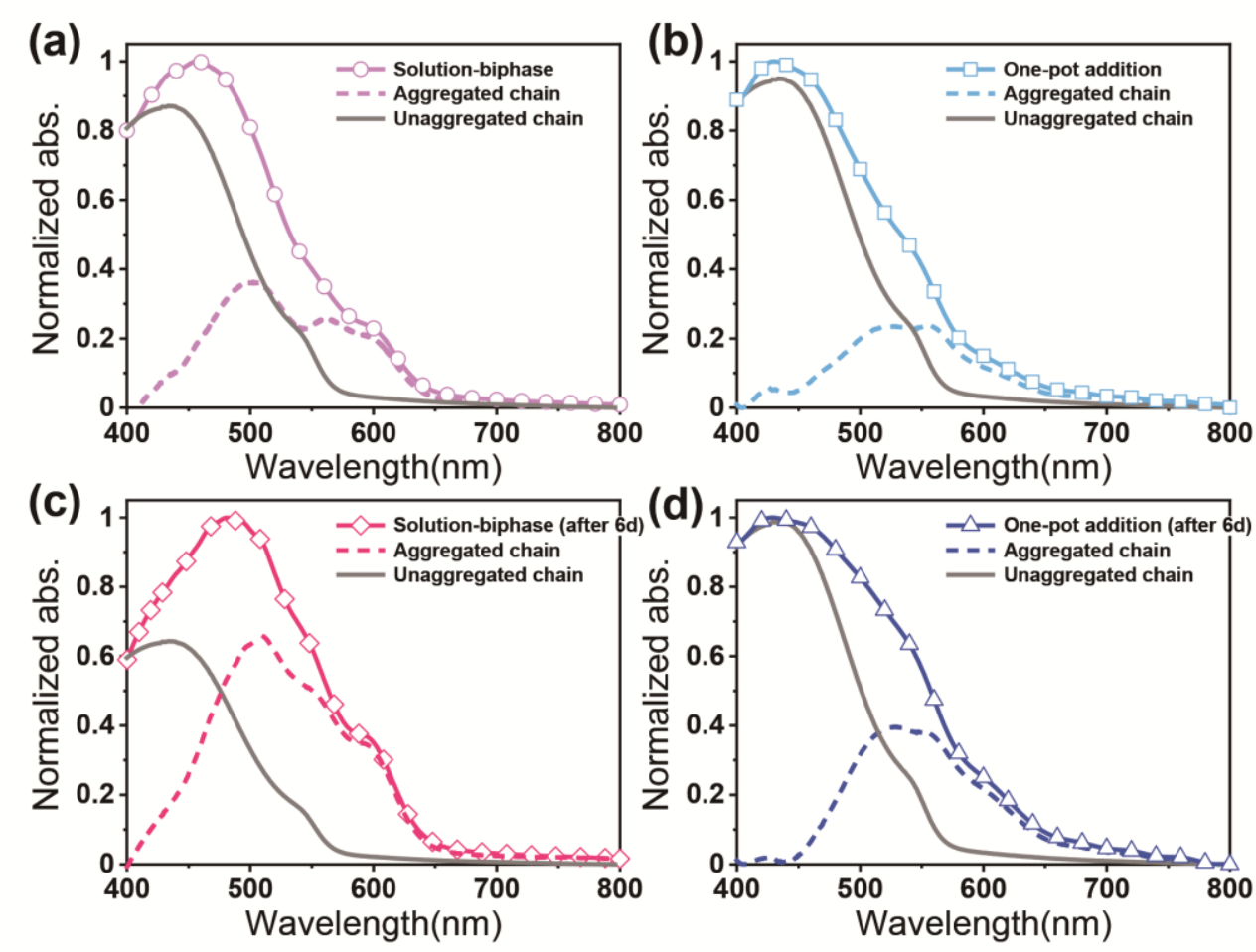

Figure S8. Experimental absorption spectra normalized to $0-2$ absorption strength for P3HT- $b-\mathrm{P} 2 \mathrm{VP}$ CP/CdSe QR formed by (a) solution-biphase method, (b) one-pot addition method, (c) solution-biphase method with aging for $6 \mathrm{~d}$, and (d) one-pot addition method with aging for $6 \mathrm{~d}$ (in 2:1 chloroform/acetonitrile (v/v)). Each absorption spectrum was decomposed into a scaled $\mathrm{CP} / \mathrm{QR}$ in chloroform (gray solid line), and aggregate spectrum (short dash line) modeled as a progression of Gaussian functions. 


\section{SUPPORTING INFORMATION}

Table S2. Fraction of unaggregated and aggregated P3HT- $b$-P2VP chains for the formation of hybrid NWs $(0.01$ $\mathrm{mg} / \mathrm{mL}$ of chloroform/acetonitrile), as calculated from absorption spectra depited in Figure S8

\begin{tabular}{ccccc}
\hline \multicolumn{1}{c}{ Methods } & $\begin{array}{c}\text { Unaggregated } \\
\text { chains [\%] }\end{array}$ & $\begin{array}{c}\text { Aggregated } \\
\text { chains [\%] }\end{array}$ & $\mathrm{A}_{0-0} / \mathrm{A}_{0-1}{ }^{a}$ & $\begin{array}{c}W^{b} \\
\text { [Free-exciton bandwidth, eV] }\end{array}$ \\
\hline Solution-biphase & 70.9 & 29.2 & 0.56 & 0.153 \\
\hline $\begin{array}{c}\text { Solution-biphase } \\
\text { after 6 d }\end{array}$ & 50.6 & 49.4 & 0.58 & 0.144 \\
\hline $\begin{array}{c}\text { One-pot addition } \\
\text { One-pot addition } \\
\text { after 6 d }\end{array}$ & 77.2 & 22.8 & 0.28 & 0.302 \\
\hline
\end{tabular}

${ }^{\bar{a}}$ Determined from the relative absorption intensity; ${ }^{b}$ Determined by using Spano's model for weakly interacting H-aggregates. ${ }^{\text {S5 }}$

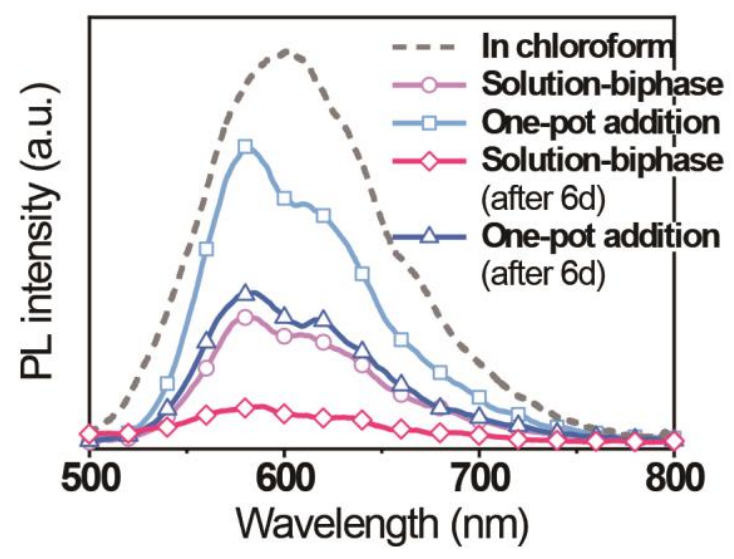

Figure S9. Photoluminescence spectra of P3HT- $b$-P2VP CP in 2:1 chloroform/acetonitrile (v/v) according to the different assembly methods $(0.1 \mathrm{mg} / \mathrm{mL})$. 


\section{SUPPORTING INFORMATION}

\section{Calculation of Location and Orientation of QR within the Hybrid NWs}

By transmission electron microtomography (TEMT), the location and orientation of QRs within the NWs were identified through the calculating the tilted angles along to the longitudinal NW axis. We have assumed that there would be a long NW axis through the center of each QRs, so we were calculated the NW axis by ImageJ software according to the pixel points of $\mathrm{x}, \mathrm{y}$ and $\mathrm{z}$ in each $\mathrm{QR}$ and indicated for a linear function. Center of $\mathrm{QRs}\left(\mathrm{C}_{\mathrm{QRs}}\right)$ was determined by an average value of pixel points of top and bottom (left and right) of QR.

(a)

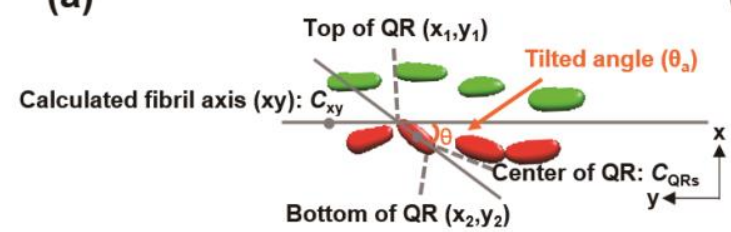

(b)

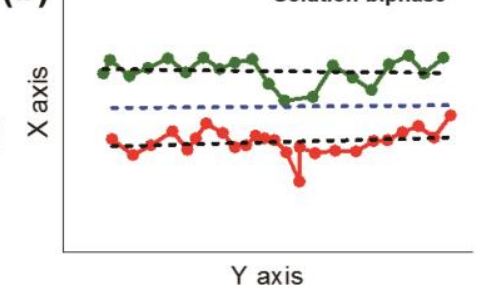

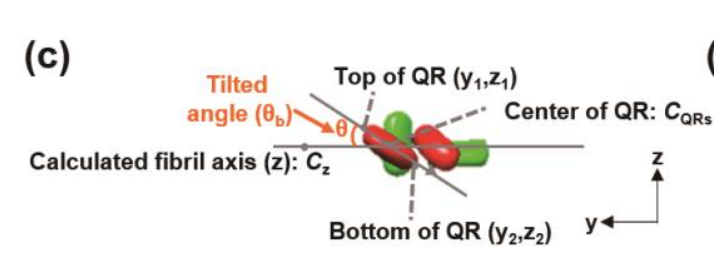

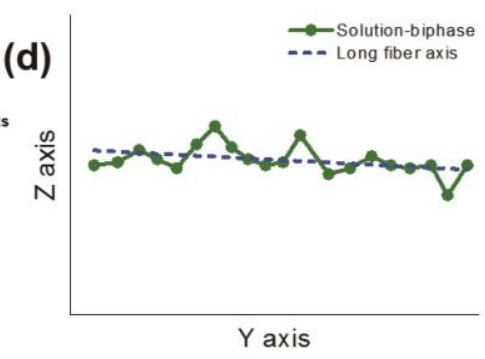

Figure S10. Calculation of offset angles of QRs within the hybrid P3HT- $b$-P2VP/QR NWs obtained from TEMT. Tilted angles of QRs within the hybrid NWs from $(\mathrm{a}, \mathrm{b}) x y$ plane and (c,d) $y z$ plane.

Table S3. Tilted angles $\left(\theta_{\mathrm{a}}, \theta_{\mathrm{b}}\right)$ of QRs within the P3HT- $b-\mathrm{P} 2 \mathrm{VP} / \mathrm{QRs}$ hybrid NWs formed by solution-biphase method

\begin{tabular}{|c|c|c|c|c|c|c|c|c|}
\hline $\begin{array}{l}\text { Number } \\
\text { of QRs }\end{array}$ & $\begin{array}{c}\text { Z_top } \\
\text { (px) }\end{array}$ & $\begin{array}{c}Z_{-} \mathbf{Z}_{\text {bottom }} \\
\text { (px) }\end{array}$ & $\begin{array}{c}\text { Z_center }_{\text {(px) }} \\
\text { Z }\end{array}$ & $\begin{array}{c}\text { Y_left } \\
\text { (px) }\end{array}$ & $\begin{array}{c}\text { Y_right } \\
\text { (px) }\end{array}$ & $\begin{array}{c}\text { Y_center } \\
\text { (px) }\end{array}$ & $\begin{array}{c}\text { tilting } \\
\text { angle }\left(\theta_{a}\right)\end{array}$ & $\begin{array}{c}\text { tilting } \\
\operatorname{angle}\left(\theta_{b}\right)\end{array}$ \\
\hline 1 & 40.0 & 69.0 & 54.5 & 40.5 & 74.5 & 57.5 & 13.2 & 0.0 \\
\hline 2 & 44.5 & 65.5 & 55.0 & 90.0 & 141.0 & 115.5 & 4.2 & 34.5 \\
\hline 3 & 34.5 & 65.5 & 50.0 & 145.5 & 190.5 & 168.0 & 27.3 & 0.0 \\
\hline 4 & 41.0 & 65.0 & 53.0 & 191.5 & 233.5 & 212.5 & 1.6 & 3.0 \\
\hline 5 & 39.0 & 70.0 & 54.5 & 240.0 & 281.0 & 260.5 & 6.8 & 62.9 \\
\hline 6 & 35.5 & 63.5 & 49.5 & 283.5 & 334.5 & 309.0 & 11.7 & 49.8 \\
\hline 7 & 24.5 & 66.5 & 45.5 & 333.0 & 375.0 & 354.0 & 44.3 & 34.1 \\
\hline 8 & 29.0 & 68.0 & 48.5 & 377.5 & 412.5 & 395.0 & 46.4 & 51.1 \\
\hline 9 & 40.0 & 62.0 & 51.0 & 414.0 & 456.0 & 435.0 & 3.25 & 69.9 \\
\hline
\end{tabular}


SUPPORTING INFORMATION

\begin{tabular}{|c|c|c|c|c|c|c|c|c|}
\hline 10 & 45.0 & 64.0 & 54.5 & 461.0 & 496.0 & 478.5 & 0.0 & 36.3 \\
\hline 11 & 41.5 & 61.5 & 51.5 & 501.0 & 542.0 & 521.5 & 6.8 & 74.9 \\
\hline 12 & 23.5 & 65.5 & 44.5 & 553.5 & 572.5 & 563.0 & 90.0 & 85.9 \\
\hline 13 & 43.0 & 67.0 & 55.0 & 610.0 & 656.0 & 633.0 & 9.2 & 57.9 \\
\hline 14 & 42.5 & 65.5 & 54.0 & 661.0 & 710.0 & 685.5 & 3.1 & 20.4 \\
\hline 15 & 37.0 & 64.0 & 50.5 & 714.0 & 763.0 & 738.5 & 3.1 & 0.0 \\
\hline 16 & 42.5 & 62.5 & 52.5 & 767.0 & 804.0 & 785.5 & 0.0 & 0.0 \\
\hline 17 & 43.0 & 65.0 & 54.0 & 810.5 & 854.5 & 832.5 & 3.4 & 16.8 \\
\hline 18 & 41.5 & 66.5 & 54.0 & 865.5 & 901.5 & 883.5 & 16.5 & 0.0 \\
\hline 19 & 44.0 & 68.0 & 56.0 & 909.0 & 940.0 & 924.5 & 0.0 & 0.0 \\
\hline 20 & 44.5 & 64.5 & 54.5 & 953.5 & 992.5 & 973.0 & 1.9 & 0.0 \\
\hline 21 & 45.0 & 69.0 & 57.0 & 40.5 & 76.5 & 58.5 & 11.8 & 40.3 \\
\hline 22 & 48.0 & 70.0 & 59.0 & 75.0 & 112.0 & 93.5 & 6.3 & 25.8 \\
\hline 23 & 46.5 & 69.5 & 58.0 & 116.5 & 154.5 & 135.5 & 0.0 & 7.4 \\
\hline 24 & 46.0 & 67.0 & 56.5 & 157.0 & 192.0 & 174.5 & 4.4 & 28.5 \\
\hline 25 & 45.5 & 66.5 & 56.0 & 197.5 & 227.5 & 212.5 & 0.0 & 7.3 \\
\hline 26 & 22.0 & 73.0 & 47.5 & 234.0 & 261.0 & 247.5 & 71.3 & 41.9 \\
\hline 27 & 47.5 & 68.5 & 58.0 & 267.5 & 314.5 & 291.0 & 1.6 & 0.0 \\
\hline 28 & 42.5 & 65.5 & 54.0 & 319.0 & 369.0 & 344.0 & 0.0 & 0.0 \\
\hline 29 & 49.0 & 70.0 & 59.5 & 374.0 & 416.0 & 395.0 & 9.6 & 0.0 \\
\hline 30 & 21.0 & 68.0 & 44.5 & 424.0 & 439.0 & 431.5 & 90.0 & 29.8 \\
\hline 31 & 25.0 & 71.0 & 48.0 & 429.0 & 446.0 & 437.5 & 90.0 & 0.0 \\
\hline 32 & 34.5 & 62.5 & 48.5 & 451.0 & 489.0 & 470.0 & 18.1 & 40.3 \\
\hline 33 & 34.5 & 65.5 & 50.0 & 486.5 & 515.5 & 501.0 & 41.6 & 32.2 \\
\hline 34 & 30.0 & 67.0 & 48.5 & 518.5 & 536.5 & 527.5 & 80.9 & 22.5 \\
\hline 35 & 40.0 & 62.0 & 51.0 & 536.0 & 562.0 & 549.0 & 33.7 & 27.5 \\
\hline 36 & 45.0 & 69.0 & 57.0 & 556.0 & 594.0 & 575.0 & 9.4 & 3.9 \\
\hline 37 & 45.5 & 64.5 & 55.0 & 589.5 & 616.5 & 603.0 & 0.0 & 0.0 \\
\hline 38 & 43.5 & 68.5 & 56.0 & 618.5 & 654.5 & 636.5 & 14.9 & 11.3 \\
\hline 39 & 41.0 & 65.0 & 53.0 & 661.5 & 703.5 & 682.5 & 0.0 & 14.9 \\
\hline 40 & 44.5 & 69.5 & 57.0 & 690.0 & 720.0 & 705.0 & 11.5 & 5.7 \\
\hline 41 & 48.0 & 70.0 & 59.0 & 714.0 & 742.0 & 728.0 & 0.0 & 33.3 \\
\hline 42 & 45.0 & 69.0 & 57.0 & 745.0 & 788.0 & 766.5 & 0.0 & 3.9 \\
\hline 43 & 40.5 & 68.5 & 54.5 & 802.5 & 844.5 & 823.5 & 0.0 & 7.0 \\
\hline 44 & 45.5 & 68.5 & 57.0 & 850.5 & 891.5 & 871.0 & 0.0 & 45.4 \\
\hline 45 & 37.5 & 66.5 & 52.0 & 899.0 & 953.0 & 926.0 & 6.7 & 4.1 \\
\hline
\end{tabular}


SUPPORTING INFORMATION

Table S4. Tilted angles $\left(\theta_{\mathrm{b}}\right)$ of QRs within the P3HT- $b$-P2VP/QRs hybrid NWs formed by one-pot addition method

\begin{tabular}{|c|c|c|c|c|c|c|c|}
\hline $\begin{array}{c}\text { Number of } \\
\text { QRs }\end{array}$ & $Z_{Z}$ top (px) & $\begin{array}{c}\text { Z_bottom } \\
(\mathbf{p x})\end{array}$ & $\begin{array}{c}\mathbf{Z}_{-} \text {center } \\
(\mathbf{p x})\end{array}$ & $\begin{array}{c}\text { Y_left } \\
\text { (px) }\end{array}$ & $\begin{array}{c}\text { Y_right } \\
(\mathbf{p x})\end{array}$ & $\begin{array}{c}Y_{-} \text {center } \\
(\mathbf{p x})\end{array}$ & $\begin{array}{r}\text { tilting } \\
\operatorname{angle}\left(\theta_{b}\right)\end{array}$ \\
\hline 1 & 65.5 & 146.5 & 106.0 & 27.5 & 48.5 & 38 & 79.8 \\
\hline 2 & 54.5 & 156.5 & 105.5 & 256.5 & 280.5 & 268.5 & -89.5 \\
\hline 3 & 60.5 & 132.5 & 96.5 & 348 & 369 & 358.5 & 77.9 \\
\hline 4 & 50.0 & 160.0 & 105.0 & 653.5 & 669.5 & 661.5 & 89.0 \\
\hline 5 & 57.0 & 158.0 & 107.5 & 773.5 & 800.5 & 787 & -88.8 \\
\hline 6 & 59.0 & 155.0 & 107.0 & 1048 & 1067 & 1057.5 & -65.8 \\
\hline 7 & 85.5 & 162.5 & 124.0 & 1198.5 & 1214.5 & 1206.5 & -87.1 \\
\hline 8 & 41.0 & 131.0 & 86.0 & 47 & 70 & 58.5 & 88.7 \\
\hline 9 & 39.5 & 155.5 & 97.5 & 141 & 167 & 154 & -89.9 \\
\hline 10 & 64.5 & 152.5 & 108.5 & 238.5 & 260.5 & 249.5 & -87.4 \\
\hline 11 & 55.0 & 148.0 & 101.5 & 435 & 460 & 447.5 & -63.9 \\
\hline 12 & 45.0 & 141.0 & 93.0 & 599.5 & 627.5 & 613.5 & 82.9 \\
\hline 13 & 40.5 & 120.5 & 80.5 & 817 & 840 & 828.5 & 47.2 \\
\hline 14 & 57.0 & 122.0 & 89.5 & 1046 & 1067 & 1056.5 & 59.3 \\
\hline 15 & 35.0 & 135.0 & 85.0 & 1186 & 1205 & 1195.5 & -86.6 \\
\hline 16 & 46.0 & 134.0 & 90.0 & 52 & 66 & 59 & 86.1 \\
\hline 17 & 88.5 & 144.5 & 116.5 & 237.5 & 249.5 & 243.5 & -84.5 \\
\hline 18 & 55.0 & 115.0 & 85.0 & 384 & 396 & 390 & -86.7 \\
\hline 19 & 79.5 & 130.5 & 105.0 & 496 & 503 & 499.5 & 83.9 \\
\hline 20 & 52.0 & 100.0 & 76.0 & 614.5 & 624.5 & 619.5 & 82.9 \\
\hline 21 & 81.5 & 122.5 & 102.0 & 671 & 686 & 678.5 & 87.3 \\
\hline 22 & 70.0 & 125.0 & 97.5 & 738 & 757 & 747.5 & 85.8 \\
\hline 23 & 97.0 & 146.0 & 121.5 & 56.5 & 71.5 & 64 & -43.8 \\
\hline 24 & 98.5 & 161.5 & 130.0 & 114 & 130 & 122 & -82.7 \\
\hline 25 & 82.0 & 132.0 & 107.0 & 359 & 372 & 365.5 & -71.6 \\
\hline 26 & 63.5 & 98.5 & 81.0 & 422.5 & 443.5 & 433 & 31.3 \\
\hline 27 & 81.5 & 137.5 & 109.5 & 533 & 550 & 541.5 & -71.6 \\
\hline 28 & 63.0 & 112.0 & 87.5 & 574 & 586 & 580 & -82.2 \\
\hline 29 & 54.0 & 109.0 & 81.5 & 666 & 682 & 674 & -88.0 \\
\hline 30 & 79.5 & 115.5 & 97.5 & 727 & 742 & 734.5 & -79.0 \\
\hline 31 & 17.5 & 113.5 & 65.5 & 11 & 42 & 26.5 & -84.9 \\
\hline 32 & 39.0 & 125.0 & 82.0 & 97 & 127 & 112 & -85.1 \\
\hline 33 & 22.0 & 105.0 & 63.5 & 182.5 & 204.5 & 193.5 & -87.5 \\
\hline 34 & 32.5 & 116.5 & 74.5 & 305.5 & 326.5 & 316 & -88.7 \\
\hline 35 & 67.5 & 145.5 & 106.5 & 445 & 463 & 454 & -84.1 \\
\hline 36 & 51.0 & 131.0 & 91.0 & 17 & 35 & 26 & 85.6 \\
\hline 37 & 35.5 & 101.5 & 68.5 & 152.5 & 180.5 & 166.5 & -88.2 \\
\hline
\end{tabular}


SUPPORTING INFORMATION

\begin{tabular}{l|l|l|c|c|c|c|c}
\hline 38 & 10.0 & 95.0 & 52.5 & 244.5 & 268.5 & 256.5 & 90 \\
39 & 26.5 & 124.5 & 75.5 & 357 & 388 & 372.5 & 80.1 \\
40 & 59.0 & 153.0 & 106.0 & 42 & 72 & 57 & -73.4 \\
41 & 61.0 & 151.0 & 106.0 & 120.5 & 138.5 & 129.5 & 83.7 \\
42 & 68.0 & 143.0 & 105.5 & 175 & 200 & 187.5 & -78.7 \\
43 & 40.5 & 110.5 & 75.5 & 227 & 249 & 238 & 78.4 \\
44 & 67.0 & 131.0 & 99.0 & 311.5 & 347.5 & 329.5 & -70.3 \\
45 & 21.0 & 103.0 & 62.0 & 382.5 & 418.5 & 400.5 & -66.3 \\
46 & 31.0 & 119.0 & 75.0 & 11 & 40 & 25.5 & 87.4 \\
47 & 46.0 & 135.0 & 90.5 & 101 & 130 & 115.5 & 65.9 \\
48 & 40.5 & 131.5 & 86.0 & 217 & 242 & 229.5 & -83.5 \\
49 & 61.0 & 136.0 & 98.5 & 321 & 350 & 335.5 & -61.4 \\
50 & 63.5 & 146.5 & 105.0 & 458.5 & 488.5 & 473.5 & -72.4 \\
\hline
\end{tabular}

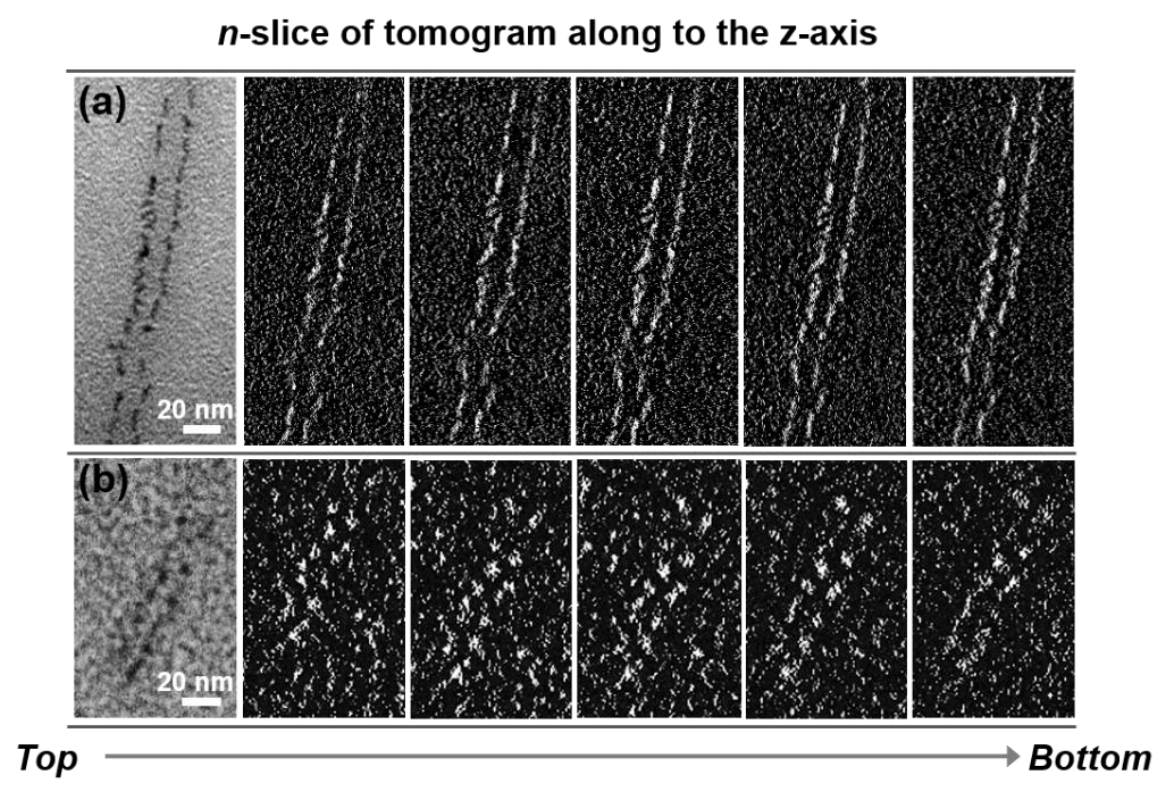

Figure S11. Galleries of selected computational xy-slices of the 3D tomographic volume of a tilt series of P3HT$b$-P2VP/QRs nanohybrids formed by (a) solution-biphase and (b) one-pot addition methods. 
SUPPORTING INFORMATION
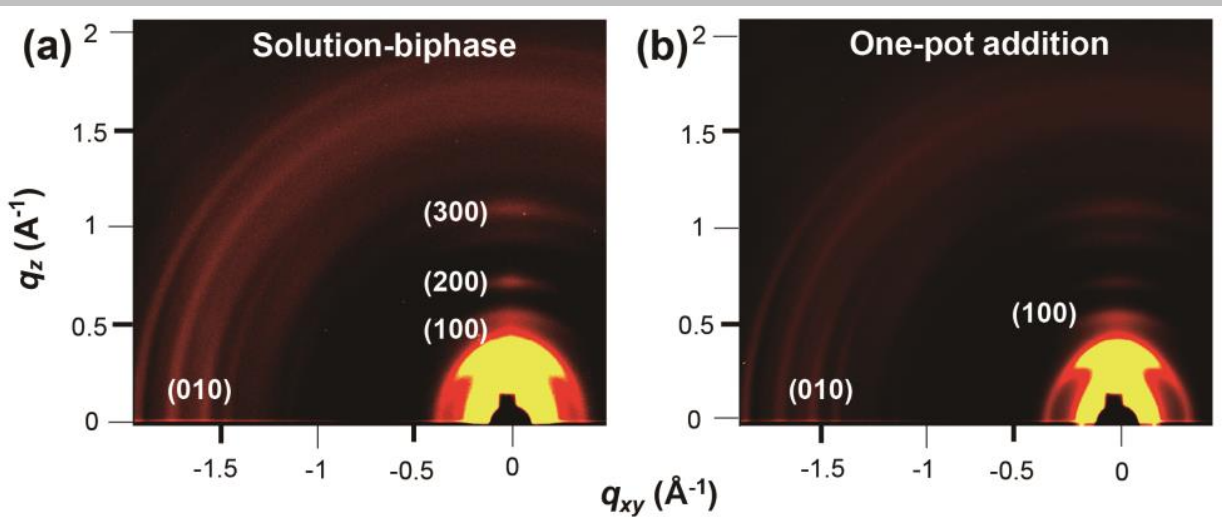

(c)

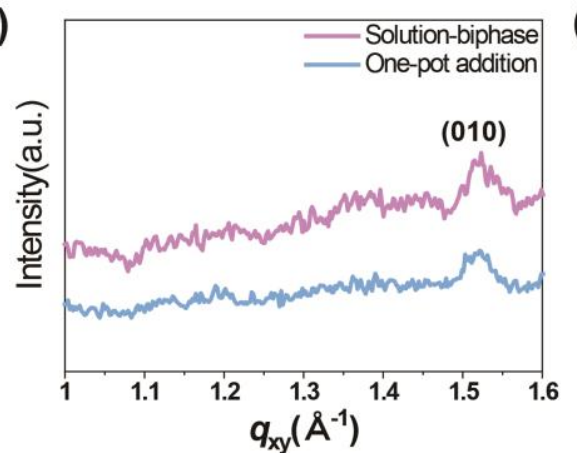

(d)

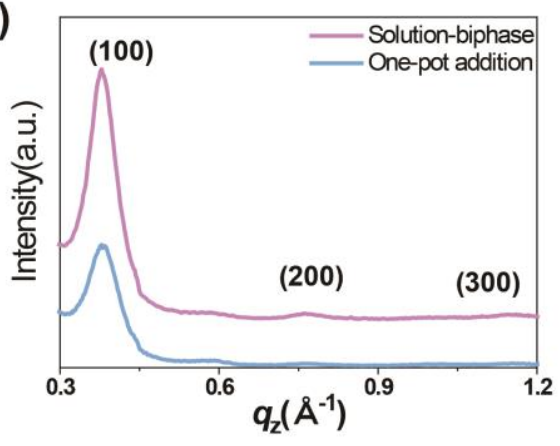

Figure S12. 2D GI-WAXS patterns of thin films as-cast from P3HT- $b-\mathrm{P} 2 \mathrm{VP} / \mathrm{QRs}$ solutions containing hybrid NWs formed by (a) solution-biphase and (b) one-pot addition methods. The in-plane $q_{\mathrm{xy}}$ and out-of-plane $q_{\mathrm{z}}$ directions are marked. (c,d) In-plane line cut $\left(q_{\mathrm{xy}}\right)$ and out-of-plane line cut $\left(q_{\mathrm{z}}\right)$ from (a) and (b), respectively.
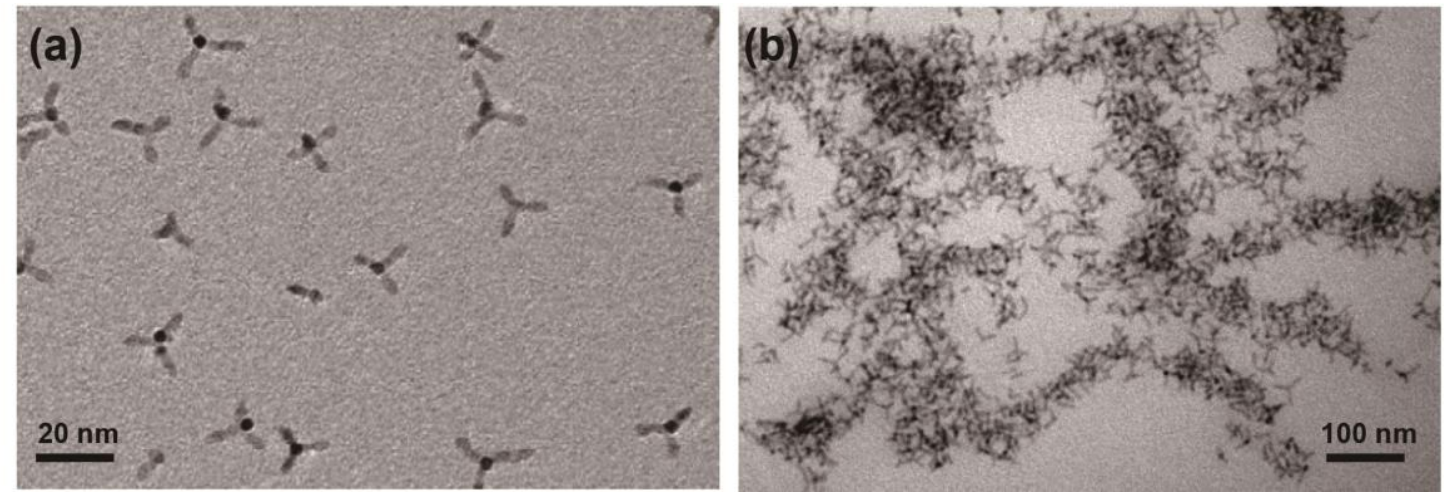

Figure S13. Synthesis of TOPO-capped (a) CdSe/CdS QTs (with seed diameter of $\sim 3 \mathrm{~nm}$ and arm length of $\sim 10$ $\mathrm{nm}$ ) and (b) coassembly with P3HT- $b$-P2VP CP in 2:1 chloroform/acetonitrile (v/v). 


\section{SUPPORTING INFORMATION}

\section{Supplementary Movies}

We provide two movies as supplementary material: 3D visualization of hybrid NWs obtained from a tilting series of 2D TEM images. Surface rendering of reconstructed volume acquired from the TEMT. In order to distinguish the association mode (end-to-end or side-by-side coupling) of well-arranged QRs along the NWs, the QRs in a $1 \mathrm{D}$ alignment were marked in red and yellow.

Movie S1.avi | P3HT- $b$-P2VP/QRs hybrid NWs formed by solution-biphase method Movie S2.avi | P3HT- $b$-P2VP/QRs hybrid NWs formed by one-pot addition method

\section{References for Supporting Information}

(S1) Kim, Y. J.; Cho, C. H.; Paek, K.; Jo, M.; Park, M.-k.; Lee, N. E.; Kim, Y.-j.; Kim, B. J.; Lee, E. Precise Control of Quantum Dot Location within the P3HT- $b$-P2VP/QD Nanowires Formed by CrystallizationDriven 1D Growth of Hybrid Dimeric Seeds. J. Am. Chem. Soc. 2014, 136 (7), 2767-2774.

(S2) Wolcott, A.; Fitzmorris, R. C.; Muzaffery, O.; Zhang, J. Z. CdSe Quantum Rod Formation Aided By In Situ TOPO Oxidation. Chem. Mater. 2010, 22 (9), 2814-2821.

(S3) Huang, J.; Kovalenko, M. V.; Talapin, D. V. Alkyl Chains of Surface Ligands Affect Polytypism of CdSe Nanocrystals and Play an Important Role in the Synthesis of Anisotropic Nanoheterostructures. J. Am. Chem. Soc. 2010, 132 (45), 15866-15868.

(S4) Talapin, D. V.; Nelson, J. H.; Shevchenko, E. V.; Aloni, S.; Sadtler, B.; Alivisatos, A. P. Seeded Growth of Highly Luminescent CdSe/CdS Nanoheterostructures with Rod and Tetrapod Morphologies. Nano Lett. 2007, 7 (10), 2951-2959.

(S5) Spano, F. C. Modeling Disorder in Polymer Aggregates: The Optical Spectroscopy of Regioregular Poly(3-Hexylthiophene) Thin Films. J. Chem. Phys. 2005, 122 (23), 234701. 